\title{
Optimization of process parameters for WEDM of Inconel 825 using grey relational analysis
}

\author{
Pawan Kumara ${ }^{a^{*}}$, Meenu ${ }^{\mathrm{a}}$ and Vineet Kumar
}

${ }^{a}$ Department of Mechanical Engineering, National Institute of Technology, Kurukshetra ${ }^{b}$ Department of Mechanical Engineering, UIET, Maharishi Dayanand University, Rohtak

\section{H R O N I C L E}

Article history:

Received October 28, 2017

Received in revised format:

January 8, 2017

Accepted January 15, 2018

Available online

January 15,2018

Keywords:

Inconel 825

Sprint cut WEDM

Machining Characteristics

Response surface methodology

Grey Relational Analysis

\begin{abstract}
A B S T R A C T
Inconel 825 is high nickel-chromium-based superalloy which retains its mechanical properties and exhibits good corrosion and oxidation resistance at elevated temperature. Inconel 825 is extensively used for making aircraft engine parts like combustor casing and turbine blades in aero space industry. This research proposed the Response Surface Methodology with GRA to optimize multiple responses during Wire-cut EDM of Inconel 825. At optimum combination of input parameters i.e. $\mathrm{A}_{4} \mathrm{~B}_{1} \mathrm{C}_{1} \mathrm{D}_{5} \mathrm{E}_{4} \mathrm{~F}_{2}$, increase in MRR from $36.13 \mathrm{~mm}^{2} / \mathrm{min}$ to $41.822 \mathrm{~mm}^{2} / \mathrm{min}$, decrease in SR from $2.842 \mu \mathrm{m}$ to $2.445 \mu \mathrm{m}$ and decrease in WWR from 0.01832 to 0.01758 was obtained. Experimental results showed that pulse-on time, wire feed, pulse-off time, and peak current significantly affected the MRR, and surface integrity of specimen and electrode with the formation of craters, pockmarks, debris, micro cracks, and recast layer. The optimal parametric combination obtained from the present study will be advantageous for working on high strength; high thermal conductivity and low melting point materials like nickel alloys.
\end{abstract}

C) 2018 by the authors; licensee Growing Science, Canada.

\section{Introduction}

Recent developments in mechanical industry have increased the demand of superalloys because of their high-strength, temperature, corrosion and oxidation resistant properties (Aggarwal et al., 2015). Superalloys retain their mechanical properties at high temperature which make them useful in marine, space, aero-engine components and other applications (AKCA and Gursel, 2013). Several generations of Inconel series have been developed such as Inconel 600, 601, 718, 800, 825 etc (AKCA and Gursel, 2013). Inconel 825 possesses superior mechanical properties compared to Inconel 718 as it provides better resistance to chloride pitting and corrosion (Thakur et al., 2014).

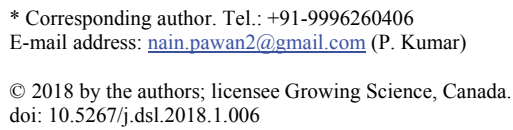


Inconel 825 is an austenitic Ni-Fe-Cr alloy with inclusion of Mo, $\mathrm{Cu}$ and $\mathrm{Ti}$ and is having large numbers of industrial applications (Rajyalakshmi and Venkata Ramaiah, 2013a). Nickel makes Alloy 825 more resistant to chloride stress-corrosion cracking. In Inconel 825, percent addition of molybdenum (2.5$3.5 \%$ ) and copper (1.5-3.0\%) makes it corrosion resistant in reducing environment (AKCA and Gursel, 2013). Titanium (0.6-1.2\%) is added to stabilize the alloy against sensitization in welded condition. High-temperature mechanical strength and high strength to weight ratio of Inconel 825 makes it extensively useful in aero-space industry for manufacturing turbine disks, combustors, blades and casing (Thakur et al., 2014).

During the machining of superalloys, the normal stresses on the cutting tool are roughly twice as high for machining of metal like steel under the same observation conditions. This results in high thermal gradient in cutting tool (Goswami and Kumar, 2014). Because of the poor thermal diffusivity of superalloys, high temperature is generated during machining at tool tip which affects the tool life adversely (Rajyalakshmi and Venkata Ramaiah, 2013b). Inconel 825 has a propensity to weld the cutting tool during machining that causes tool failure. Because of high toughness and hardness, the machining of this material with conventional method is very difficult (Choi et al., 2008).

Wire electrical discharge machining (WEDM) is a non-conventional thermoelectric modern machining process and is favored over conventional methods for machining of Inconel 825 (Rajyalakshmi and Venkata Ramaiah, 2012). These non-conventional machining methods satisfy the production and quality requirements with improved precision and accuracy. The machining performance is measured by using multi-objective optimization technique in terms of MRR, SR and WWR (Aggarwal et al., 2015). It is reported by various studies that for obtaining optimum machining characteristics, selection of desired machining parameters is very important (Somashekhar et al., 2010; Goswami and Kumar, 2014). Generally, the values of input parameters are selected on the basis of machine manuals but it does not ensure optimal machining performances. Therefore, the selection of best parametric combination is useful to get required performance values for the product (Rajyalakshmi and Venkata Ramaiah, 2013b).

Conventional experimental design methods require a large amount of experimental data for determining the best combination of parameters, which is expensive and prolonged. To overcome these problems, researchers applied factorial design named Design of Experiment. Taguchi's methodology has been used in various studies to obtain best combination of parameters for desired machining performances (Mahapatra and Patnaik, 2007; Chhabra et al., 2014; Patra et al., 2015; Singh and Singh, 2015; Dabade and Karidkar, 2016). Response surface methodology is a better approach than taguchi method as it can help to find the nearest range of machining parameters beyond or within the range of level of factors. Also, RSM is a more mathematical approach as it identifies the interaction between the variables rather than investigating the effect of individual parameters (Raykundaliya and Shanubhogue, 2015).

Optimum machining parameters selection of WEDM, avoid the wire breakage problem and surface roughness because improperly selected parameters reduce productivity and quality requirements. A suitable modeling and optimization technique is used to establish the relationship between output and input parameters. In this study, wire cut EDM parameters are optimized with consideration to multiple performance characteristics such as material removal or cutting rate (MRR), wire wear ratio (WWR) and surface roughness (SR). Pulse-on time $\left(\mathrm{T}_{\text {on }}\right)$, pulse-off time $\left(\mathrm{T}_{\text {off }}\right)$, peak current (IP), gap voltage (SV), wire feed rate (WF) and wire tension (WT) are the parameters that influences the machining (Aggarwal et al., 2015).

As evident from the literature review, very few authors focused on standardization of machining characteristics of WEDM with MRR and SR using Inconel 825 (Goswami and Kumar, 2014). However, no study has been reported on investigation of wire wear ratio. Thus, the objective of the present work is to optimize the machining characteristics of WEDM using Inconel 825 in order to satisfy the production and quality requirements. 


\section{Materials and Methods}

\subsection{Work material}

In the present study, Inconel 825, a high mechanical strength material is used as experimental work material. The dimension of the workpiece used for experimentation is $150 \mathrm{~mm}$ length, $150 \mathrm{~mm}$ breadth and $10 \mathrm{~mm}$ thickness. The chemical and physical property of the Inconel 825 is shown in Table 1. Fig. 1 shows the work material before machining (Fig. 1A) and after machining respectively (Fig. 1B). Fig. $2 \mathrm{~A}$ shows the dimensions of the specimen $(5 \mathrm{~mm} \times 5 \mathrm{~mm} \times 10 \mathrm{~mm})$ cut from the workpiece by WEDM process. The image of specimen after machining of workpiece is shown in Fig. 2B.

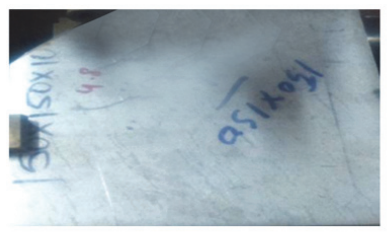

A

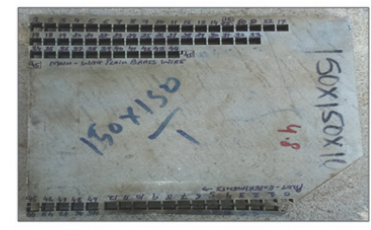

B

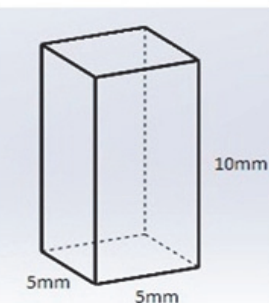

A

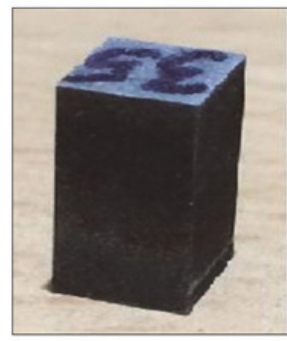

B
Fig. 1. Workpiece (Inconel 825) A) before machining B) after machining

Fig. 2. Inconel $825 \mathrm{~A})$ Actual dimensions of the specimen B) Image of the specimen after machining

Table 1

Properties of Inconel 825

\begin{tabular}{|c|c|}
\hline Chemical composition of Incon & \\
\hline Element & Content (\%) \\
\hline $\mathrm{Ni}$ & $38-46$ \\
\hline $\mathrm{Fe}$ & 22 \\
\hline $\mathrm{Cr}$ & $19.5-23.5$ \\
\hline Mo & $2.5-3.5$ \\
\hline $\mathrm{Cu}$ & $1.5-3.0$ \\
\hline $\mathrm{Ti}$ & $0.6-1.2$ \\
\hline $\mathrm{C}$ & $0.05 \max$ \\
\hline $\mathrm{P}$ & $0.02 \max$ \\
\hline S & $0.03 \max$ \\
\hline $\mathrm{Mg}$ & $1.0 \max$ \\
\hline Physical properties of Inconel & \\
\hline Property & Metric \\
\hline Density & $8.14 \mathrm{~g} / \mathrm{cm}^{3}$ \\
\hline Melting Point & $1400^{\circ} \mathrm{C}$ \\
\hline Coefficient of expansion & $14.0 \mathrm{~m} / \mathrm{m} /{ }^{\circ} \mathrm{C}\left(20-100^{\circ} \mathrm{C}\right)$ \\
\hline Modulus of rigidity & $75.9 \mathrm{~N} / \mathrm{mm}^{2}$ \\
\hline Modulus of elasticity & $196 \mathrm{kN} / \mathrm{mm}^{2}$ \\
\hline
\end{tabular}

\subsection{Mechanism of WEDM}

Experiments were performed using sprint cut CNC WEDM machine tool (Fig. 3A). In this machine tool all axes are numerically controlled. The program is written in CNC code (machine language) for which a $5 \mathrm{~mm} \times 5 \mathrm{~mm}$ square is designed and fed through control panel. The electrode material is a single-strand plain brass wire of diameter $0.25 \mathrm{~mm}$ and is fed through the workpiece continuously by upper and lower head mechanism. The upper head supply the fresh wire under tension through the 
workpiece and lower head receive the used wire after machining (Fig. 3B). The workpiece is mounted with the help of a fixture on the machine table which can move in $x-y$ directions.

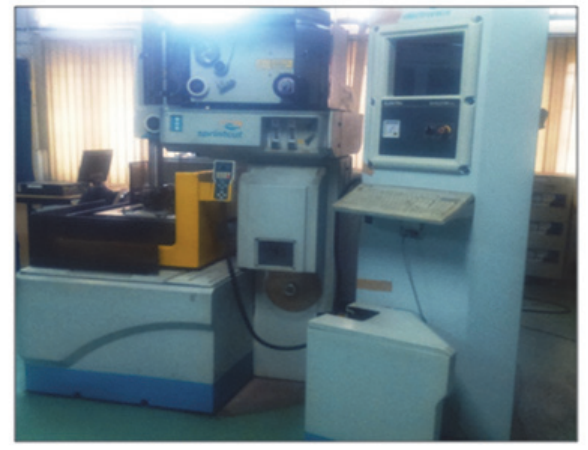

A

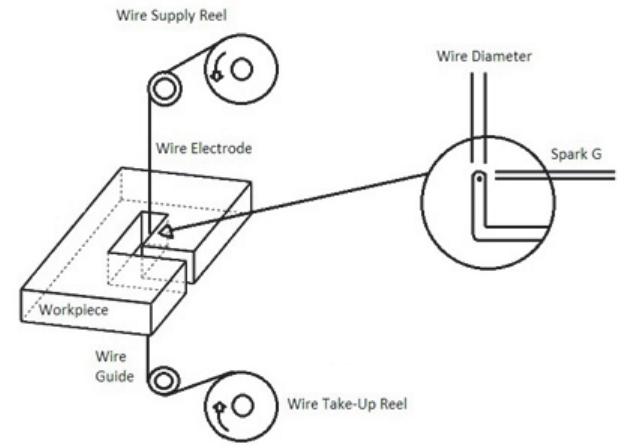

B

Fig. 3. WEDM machine A) Experimental setup B) wire cut EDM process

WEDM is a thermo-electric process in which a suitable gap is maintained $(0.025-0.5 \mathrm{~mm})$ between wire and the workpiece and breakdown voltage is applied to generate the spark in between the gap. The material is removed from wire and workpiece by the thermoelectric erosion process. When an electric field is applied, the gap voltage reaches the breakdown voltage and high power spark is produced which increase the temperature to about $8000-10000^{\circ} \mathrm{C}$ in between the smallest gap where plasma zone occurs. During machining, the debris produced by the erosion process is flushed by the dielectric fluid which is continuously fed by upper and lower nozzles to the sparking area along the wire. The wire and workpiece erosion is collected at the bottom of the collection tank and then discarded. Because of the small craters produced in wire during machining, it cannot be reused again.

The machining performance can be measured in terms of MRR, SR and WWR. MRR $\left(\mathrm{mm}^{2} / \mathrm{min}\right)$ is obtained by multiplying the cutting speed with thickness of the specimen. Control panel of the machine is used to display the cutting speed in $\mathrm{mm} / \mathrm{min}$ and time taken for machining is noted down manually for every run. The surface roughness $(\mathrm{Ra})$ of machined specimen is measured in $\mu \mathrm{m}$ using Accretech's surfcomflex instrument SJ-301 (Fig. 4). Least count of the instrument is $0.8 \mathrm{~mm}$. A sampling length of $5 \mathrm{~mm}$ has been selected in one step for the measurement.

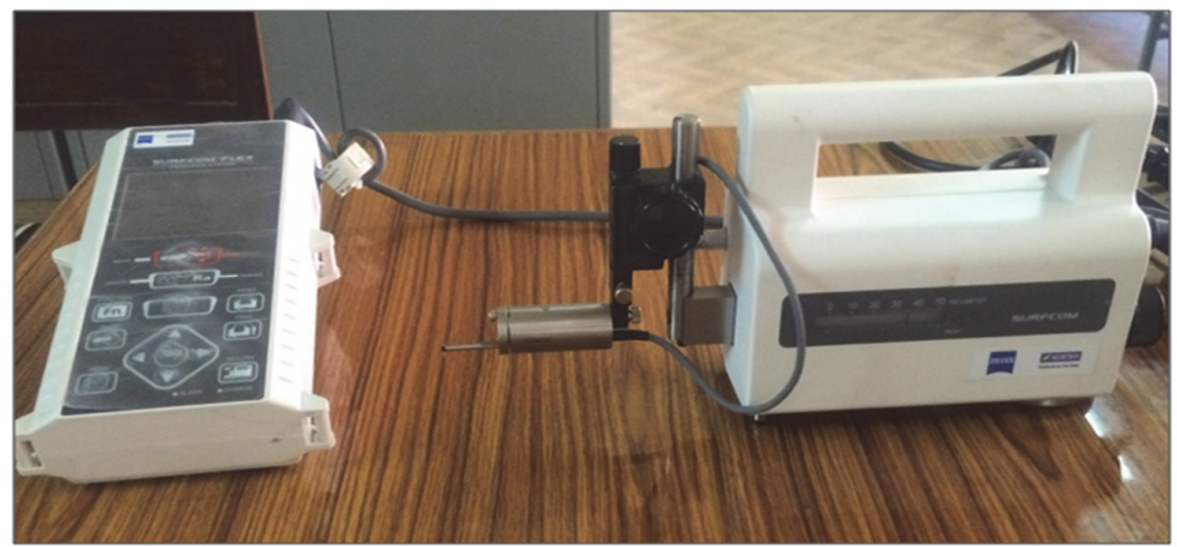

Fig. 4. Photographic view of Surfcomflex instrument SJ-301

Wire wear ratio is measured by using initial wire weight and used wire weight. It is the ratio of difference between initial wire weight and used wire weight to the initial wire weight. Used wire weight for one specimen is directly measured by using weighing machine. The least count of the weighing machine is $0.02 \mathrm{~g}$. Fresh wire weight used for one specimen is measured by calculating the length of used wire. One meter length of fresh wire has $0.400 \mathrm{mg}$ weight. The fresh wire weight is obtained by multiplying the length of used wire to the weight of the one meter fresh wire. 


\subsection{Selection of machining parameter and ranges}

To avoid the wire breakage and poor work surface problem, proper selection of input parameters of WEDM is an important step. Selection of nearest range of input parameters of WEDM, not only avoid such problems but also increases the productivity and surface quality. Various machining parameters including $\mathrm{T}_{\text {on }}, \mathrm{T}_{\text {off, }}, \mathrm{IP}, \mathrm{SV}, \mathrm{WF}$ and $\mathrm{WT}$ was taken in this study. The nearest ranges of machining parameters were chosen on the basis of pilot experiments and machine manual. These process parameters are leveled by central composite design system MRR, SR and WWR are considered as performance criteria.

\subsection{Design of Experiments}

The experiment is designed using Design-Expert software version 9 (Stat-Ease, 9). Central Composite Design (CCD) is an important branch of Response Surface Methodology (RSM) intended for the designing of experiments and develops mathematical and statistical relationship between input parameters and response variables (MRR, SR and WWR). CCD is the most extensive application of RSM due to its elasticity, ability to perform experiments consecutively and to develop empirical statistical modeling between input variables and responses. In CCD, each variable is varied at five different levels $(-2,-1,0,1,2)$. The present design consists of 32 factorial points, 12 axial points and 8 centre points and experiments were performed. Randomizations of experimental runs are used to avoid any type of human mistakes. The actual and coded values of the variables are shown in Table 2 while the constant parameters are given in Table 3.

Table 2

Experimental factors and their levels for wire electrical discharge machining process

\begin{tabular}{|c|c|c|c|c|c|c|c|c|c|}
\hline S. No. & Symbol & Parameter & Factor & $\frac{\text { Level } 1}{(-2)}$ & $\frac{\text { Level } 2}{(-1)}$ & $\frac{\text { Level } 3}{(0)}$ & $\frac{\text { Level } 4}{(1)}$ & $\frac{\text { Level } 5}{(2)}$ & Ranges \\
\hline 1 & A & Pulse on time & $\mathrm{T}_{\text {on }}(\mu \mathrm{s})$ & 107 & 109 & 111 & 113 & 115 & $107-115$ \\
\hline 2 & B & Pulse off time & $\mathrm{T}_{\mathrm{off}}(\mu \mathrm{s})$ & 32 & 35 & 38 & 41 & 44 & $32-44$ \\
\hline 3 & $\mathrm{C}$ & Gap Voltage & CS (Volts) & 42 & 46 & 50 & 54 & 58 & $42-58$ \\
\hline 4 & $\mathrm{D}$ & Peak Current & IP (Amp) & 110 & 120 & 130 & 140 & 150 & $110-150$ \\
\hline 5 & $\mathrm{E}$ & Wire Tension & WT (kg-f) & 8 & 9 & 10 & 11 & 12 & $8-12$ \\
\hline 6 & $\mathrm{~F}$ & Wire feed rate & $\mathrm{WF}(\mathrm{m} / \mathrm{min})$ & 4 & 5 & 6 & 7 & 8 & $4-8$ \\
\hline
\end{tabular}

Table 3

Constant parameters for wire electrical discharge machining process

\begin{tabular}{ll}
\hline Parameters & Values \\
\hline Wire material & Plain brass wire \\
Workpiece material & Inconel 825 \\
Workpiece hardness & $81-82$ \\
Dielectric fluid & Deionized water \\
Conductivity of dielectric & $20 \mathrm{mho}$ \\
Flushing pressure & $15 \mathrm{~kg} / \mathrm{cm}^{2}$ \\
Pulse peak voltage & $110 \mathrm{DC}$ \\
\hline
\end{tabular}

\subsection{Grey Relational Analysis (GRA)}

GRA provides an effective solution to the multiple performance characteristics. GRA technique provides relation between machining parameters and responses. GRA uses Grey Relation Grade system which is ranking order scheme among control factors and grey relational coefficient of response 
variables. MRR is considered as "higher-the-better" whereas SR and WWR are considered as "lowerthe-better".

STEP-1: The maximum value, minimum value and their difference were obtained from the results of RSM.

STEP-2: Normalization of the data sequence was performed using equation 1 (larger the better) and Eq. (2) (smaller the better) for MRR and SR respectively.

$$
\begin{aligned}
& x_{i}^{*}(k)=\frac{x_{i}^{0}(k)-\min x_{i}^{0}(k)}{\max x_{i}^{0}(k)-\min x_{i}^{0}(k)} \\
& x_{i}^{*}(k)=\frac{\max x_{i}^{0}(k)-x_{i}^{0}(k)}{\max x_{i}^{0}(k)-\min x_{i}^{0}(k)}
\end{aligned}
$$

where,

$$
\begin{aligned}
& x_{i}^{*}(k)=\text { value after grey relational generation. } \\
& \min x_{i}^{0}(k)=\text { smallest value of } x_{i}^{0}(k) \\
& \max x_{i}^{0}(k)=\text { largest value of } x_{i}^{0}(k)
\end{aligned}
$$

STEP-3: In this step, the deviation sequence was calculated by subtracting respective normalized value from one.

STEP-4: The grey relational coefficient $\left(\xi_{i}(k)\right)$ was determined by using Eq. (3).

$$
\xi_{i}(k)=\frac{\Delta_{\min }+\varsigma \Delta_{\max }}{\Delta_{0 i}(k)+\varsigma \Delta_{\max }}
$$

where,

$\varsigma \in[0-1]$ is the distinguishing coefficient, 0.5 is widely accepted;

$\Delta_{0 i}=\left\|x_{0}^{*}(k)-x_{i}^{*}(k)\right\|$ is the difference in absolute value between $x_{0}^{*}(k)$ and $x_{i}^{*}(k)$;

$x_{i}^{*}(k)$ denotes the reference sequence; $x_{j}^{*}(k)$ denotes the comparability sequence;

$\Delta_{\min }=\min _{\forall j \in i} \min _{\forall k}\left\|x_{0}^{*}(k)-x_{j}^{*}(k)\right\|$ is the smallest value of $\Delta_{0 i} ;$ is the largest value of $\Delta_{0 i}$.

STEP-5: The overall evaluation of the multi objective problem depends upon Grey relational grade (GRG). Mean value of the grey relational coefficient for each response was calculated for determining the GRG. The GRG with highest rank determine the optimum combination of the experiments.

\subsection{Confirmation test}

To confirm the MRR, SR and WWR an additional experiment has been conducted using grey prediction theory. The predicted error $(\%)$ is calculated by the following:

$$
\text { Prediction error }=\frac{(\text { Experimental result }- \text { Predicted result })}{\text { Experimental result }} \times 100
$$

\subsection{Scanning electron micrographs of Inconel 825 specimens}

All measurement related to surface micrograph were performed on JEOL scanning electron Microscope (Model 6100, JEOL, USA); a profile measuring microscope that determine the surface microstructures, formation of recast layer and heat-affected zone of the work material machined with WEDM. Etching 
process of machined sample was carried out with krolls reagent $(2 \%(\mathrm{v} / \mathrm{v})$ hydrofluoric acid, $10 \%(\mathrm{v} / \mathrm{v})$ nitric acid). Then, the samples were cleaned using acetone $\left(\mathrm{CH}_{3}\right)_{2} \mathrm{CO}$.

\section{Results and Discussion}

Nowadays, there is rising demand of nickel based superalloys which retain their mechanical properties under severe conditions and exhibits good surface quality (Singha et al., 2015). Due to the retention of their mechanical properties at high-temperature, these superalloys are used in aero space industry and other applications (Thakur et al., 2014). Most of the studies focused on Inconel 718 with respect to different cutting conditions (Aggarwal et al., 2015). However, there are very few reports on machining of Inconel 825 (Thakur et al., 2014). Therefore, Inconel 825 is used as work material for the present study.

Table 4

Central composite design of RSM and their responses

\begin{tabular}{|c|c|c|c|c|c|c|c|c|c|}
\hline Experiment No. & $\mathbf{T}_{\text {on }}$ & $\mathbf{T}_{\text {off }}$ & SV & IP & WT & WF & $\begin{array}{c}\text { MRR } \\
\left(\mathrm{mm}^{2} / \mathrm{min}\right)\end{array}$ & $\mathrm{SR}(\mu \mathrm{m})$ & WWR \\
\hline 1 & 0 & 0 & 0 & 0 & 0 & -2 & 21.27 & 2.618 & 0.21966 \\
\hline 2 & 0 & 0 & 0 & 0 & 0 & 0 & 20.44 & 2.306 & 0.01531 \\
\hline 3 & -1 & -1 & 1 & 1 & 1 & 1 & 18.59 & 2.453 & 0.01347 \\
\hline 4 & 1 & -1 & 1 & -1 & 1 & 1 & 27.79 & 2.967 & 0.0041 \\
\hline 5 & 1 & 1 & 1 & -1 & -1 & 1 & 20.63 & 2.766 & 0.01908 \\
\hline 6 & 1 & -1 & 1 & -1 & -1 & -1 & 27.69 & 2.867 & 0.01425 \\
\hline 7 & 1 & 1 & -1 & 1 & -1 & 1 & 20.06 & 2.711 & 0.00337 \\
\hline 8 & 0 & 0 & 0 & 0 & 0 & 0 & 21.97 & 2.673 & 0.13256 \\
\hline 9 & -1 & 1 & -1 & -1 & -1 & 1 & 17.01 & 2.436 & 0.01848 \\
\hline 10 & -1 & -1 & 1 & 1 & -1 & -1 & 21.34 & 2.668 & 0.01099 \\
\hline 11 & 1 & 1 & -1 & 1 & 1 & -1 & 31.81 & 2.793 & 0.00976 \\
\hline 12 & -1 & 1 & 1 & 1 & -1 & 1 & 16.17 & 2.716 & 0.08732 \\
\hline 13 & -1 & 1 & -1 & 1 & -1 & -1 & 20.23 & 2.732 & 0.02236 \\
\hline 14 & 1 & -1 & -1 & -1 & -1 & 1 & 27.63 & 2.678 & 0.00032 \\
\hline 15 & 0 & 0 & 0 & 0 & 0 & 0 & 21.89 & 2.911 & 0.03677 \\
\hline 16 & 0 & 0 & 0 & 0 & 0 & 0 & 20.41 & 2.875 & 0.03255 \\
\hline 17 & -1 & -1 & -1 & 1 & -1 & 1 & 28.94 & 2.442 & 0.17573 \\
\hline 18 & 2 & 0 & 0 & 0 & 0 & 0 & 31.25 & 3.32 & 0.01093 \\
\hline 19 & 1 & -1 & -1 & 1 & 1 & 1 & 34.72 & 2.84 & 0.04773 \\
\hline 20 & 0 & -2 & 0 & 0 & 0 & 0 & 30.87 & 2.613 & 0.01845 \\
\hline 21 & 0 & 2 & 0 & 0 & 0 & 0 & 17.19 & 2.667 & 0.01298 \\
\hline 22 & 1 & -1 & 1 & 1 & 1 & -1 & 31.42 & 3.271 & 0.02028 \\
\hline 23 & -1 & 1 & 1 & 1 & 1 & -1 & 18.55 & 2.514 & 0.00291 \\
\hline 24 & 0 & 0 & 0 & 0 & 0 & 0 & 35.93 & 4.204 & 0.01573 \\
\hline 25 & 1 & 1 & -1 & -1 & 1 & 1 & 28.95 & 3.299 & 0.29061 \\
\hline 26 & -1 & -1 & -1 & -1 & -1 & -1 & 25.79 & 2.721 & 0.23103 \\
\hline 27 & -1 & -1 & 1 & -1 & 1 & -1 & 19.92 & 2.489 & 0.01481 \\
\hline 28 & 0 & 0 & 0 & 0 & -2 & 0 & 24.09 & 2.767 & 0.00394 \\
\hline 29 & 0 & 0 & 0 & 2 & 0 & 0 & 27.08 & 2.684 & 0.01292 \\
\hline 30 & -1 & -1 & 1 & -1 & -1 & 1 & 20.21 & 2.681 & 0.02832 \\
\hline 31 & 1 & 1 & 1 & 1 & 1 & 1 & 27.68 & 2.742 & 0.00514 \\
\hline 32 & 0 & 0 & 0 & 0 & 2 & 0 & 26.05 & 2.792 & 0.00823 \\
\hline 33 & 0 & 0 & 0 & 0 & 0 & 0 & 24.59 & 3.074 & 0.00545 \\
\hline 34 & -1 & -1 & -1 & 1 & 1 & -1 & 25.47 & 2.622 & 0.01644 \\
\hline 35 & 0 & 0 & 0 & 0 & 0 & 0 & 23.94 & 2.461 & 0.01049 \\
\hline 36 & 0 & 0 & -2 & 0 & 0 & 0 & 25.57 & 2.594 & 0.00661 \\
\hline 37 & 1 & 1 & 1 & 1 & -1 & -1 & 33.28 & 2.892 & 0.28845 \\
\hline 38 & -1 & 1 & -1 & 1 & 1 & 1 & 20.52 & 2.415 & 0.00404 \\
\hline 39 & -1 & 1 & 1 & -1 & -1 & -1 & 16.7 & 2.521 & 0.01463 \\
\hline 40 & 1 & 1 & 1 & -1 & 1 & -1 & 24.46 & 2.263 & 0.00297 \\
\hline 41 & -1 & 1 & 1 & -1 & 1 & 1 & 16.71 & 2.318 & 0.01062 \\
\hline 42 & -1 & -1 & -1 & -1 & 1 & 1 & 23.14 & 2.485 & 0.00801 \\
\hline 43 & 0 & 0 & 2 & 0 & 0 & 0 & 19.61 & 2.734 & 0.01789 \\
\hline 44 & 1 & 1 & -1 & -1 & -1 & -1 & 28.39 & 2.805 & 0.00616 \\
\hline 45 & 1 & -1 & -1 & -1 & 1 & -1 & 34.56 & 2.827 & 0.00815 \\
\hline 46 & -2 & 0 & 0 & 0 & 0 & 0 & 14.7 & 3.94 & 0.03203 \\
\hline 47 & 0 & 0 & 0 & 0 & 0 & 2 & 25.77 & 2.94 & 0.01582 \\
\hline 48 & 1 & -1 & -1 & 1 & -1 & -1 & 36.14 & 2.833 & 0.02691 \\
\hline 49 & 1 & -1 & 1 & 1 & -1 & 1 & 36.13 & 2.842 & 0.01832 \\
\hline 50 & 0 & 0 & 0 & 0 & 0 & 0 & 29.48 & 2.853 & 0.00853 \\
\hline 51 & -1 & 1 & -1 & -1 & 1 & -1 & 23.67 & 2.64 & 0.1215 \\
\hline 52 & 0 & 0 & 0 & -2 & 0 & 0 & 28.08 & 2.748 & 0.08998 \\
\hline
\end{tabular}


Therefore, in this study, optimization of WEDM parameters has been done by employing RSM in combination with GRA using Inconel 825 as work material. A single grey relational grade system was used to analyze the effects of control factors on performance characteristics. Using half fraction of RSM, fifty two experiments runs were performed to obtain best input factor level combinations (Table 4). Analysis of input factors was carried out according to the three response variables viz. MRR, SR and WWR. The results of RSM were analyzed by grey relational analysis.

\subsection{Grey Relational Analysis of RSM results}

The maximum value, minimum value and their difference were obtained from the results of RSM. The normalization of the results was carried out by using equation 1 and 2 and then deviation sequence was calculated by subtracting respective normalized value from one.

Table 5

Grey Relational Coefficient and Grade

\begin{tabular}{|c|c|c|c|c|c|c|c|c|c|c|c|}
\hline \multirow[b]{2}{*}{ Ex. No. } & \multicolumn{6}{|c|}{ Control Factors } & \multicolumn{3}{|c|}{ Grey Relational Coefficient } & \multirow{2}{*}{ GRG } & \multirow[t]{2}{*}{ Order } \\
\hline & $\mathbf{T}_{\text {on }}$ & $T_{\text {off }}$ & SV & IP & WT & WF & MRR & SR & WWR & & \\
\hline 1 & 111 & 38 & 50 & 130 & 10 & 4 & 0.419 & 0.732 & 0.398 & 0.516 & 50 \\
\hline 2 & 111 & 38 & 50 & 130 & 10 & 6 & 0.406 & 0.958 & 0.906 & 0.757 & 7 \\
\hline 3 & 109 & 35 & 54 & 140 & 11 & 7 & 0.379 & 0.836 & 0.917 & 0.711 & 21 \\
\hline 4 & 113 & 35 & 54 & 120 & 11 & 7 & 0.562 & 0.580 & 0.975 & 0.705 & 24 \\
\hline 5 & 113 & 41 & 54 & 120 & 9 & 7 & 0.409 & 0.659 & 0.886 & 0.651 & 38 \\
\hline 6 & 113 & 35 & 54 & 120 & 9 & 5 & 0.559 & 0.616 & 0.912 & 0.696 & 29 \\
\hline 7 & 113 & 41 & 46 & 140 & 9 & 7 & 0.400 & 0.684 & 0.979 & 0.688 & 31 \\
\hline 8 & 111 & 38 & 50 & 130 & 10 & 6 & 0.431 & 0.703 & 0.523 & 0.552 & 47 \\
\hline 9 & 109 & 41 & 46 & 120 & 9 & 7 & 0.359 & 0.849 & 0.889 & 0.699 & 28 \\
\hline 10 & 109 & 35 & 54 & 140 & 9 & 5 & 0.420 & 0.706 & 0.932 & 0.686 & 32 \\
\hline 11 & 113 & 41 & 46 & 140 & 11 & 5 & 0.712 & 0.647 & 0.939 & 0.766 & 5 \\
\hline 12 & 109 & 41 & 54 & 140 & 9 & 7 & 0.349 & 0.682 & 0.625 & 0.552 & 48 \\
\hline 13 & 109 & 41 & 46 & 140 & 9 & 5 & 0.403 & 0.674 & 0.868 & 0.648 & 39 \\
\hline 14 & 113 & 35 & 46 & 120 & 9 & 7 & 0.557 & 0.700 & 1.000 & 0.753 & 9 \\
\hline 15 & 111 & 38 & 50 & 130 & 10 & 6 & 0.429 & 0.600 & 0.799 & 0.609 & 44 \\
\hline 16 & 111 & 38 & 50 & 130 & 10 & 6 & 0.405 & 0.613 & 0.818 & 0.612 & 43 \\
\hline 17 & 109 & 35 & 46 & 140 & 9 & 7 & 0.598 & 0.844 & 0.453 & 0.632 & 41 \\
\hline 18 & 115 & 38 & 50 & 130 & 10 & 6 & 0.687 & 0.479 & 0.932 & 0.699 & 27 \\
\hline 19 & 113 & 35 & 46 & 140 & 11 & 7 & 0.883 & 0.627 & 0.754 & 0.755 & 8 \\
\hline 20 & 111 & 30 & 50 & 130 & 10 & 6 & 0.670 & 0.735 & 0.889 & 0.765 & 6 \\
\hline 21 & 111 & 45 & 50 & 130 & 10 & 6 & 0.361 & 0.706 & 0.920 & 0.662 & 36 \\
\hline 22 & 113 & 35 & 54 & 140 & 11 & 5 & 0.694 & 0.491 & 0.879 & 0.688 & 39 \\
\hline 23 & 109 & 41 & 54 & 140 & 11 & 5 & 0.379 & 0.795 & 0.982 & 0.719 & 20 \\
\hline 24 & 111 & 38 & 50 & 130 & 10 & 6 & 0.981 & 0.333 & 0.904 & 0.739 & 13 \\
\hline 25 & 113 & 41 & 46 & 120 & 11 & 7 & 0.599 & 0.484 & 0.333 & 0.472 & 52 \\
\hline 26 & 109 & 35 & 46 & 120 & 9 & 5 & 0.509 & 0.679 & 0.386 & 0.525 & 49 \\
\hline 27 & 109 & 35 & 54 & 120 & 11 & 5 & 0.398 & 0.811 & 0.909 & 0.706 & 23 \\
\hline 28 & 111 & 38 & 50 & 130 & 8 & 6 & 0.471 & 0.658 & 0.976 & 0.702 & 26 \\
\hline 29 & 111 & 38 & 50 & 150 & 10 & 6 & 0.542 & 0.697 & 0.920 & 0.720 & 19 \\
\hline 30 & 109 & 35 & 54 & 120 & 9 & 7 & 0.402 & 0.699 & 0.838 & 0.646 & 40 \\
\hline 31 & 113 & 41 & 54 & 140 & 11 & 7 & 0.559 & 0.670 & 0.968 & 0.732 & 16 \\
\hline 32 & 111 & 38 & 50 & 130 & 12 & 6 & 0.515 & 0.647 & 0.948 & 0.704 & 25 \\
\hline 33 & 111 & 38 & 50 & 130 & 10 & 6 & 0.481 & 0.545 & 0.966 & 0.664 & 35 \\
\hline 34 & 109 & 35 & 46 & 140 & 11 & 5 & 0.501 & 0.730 & 0.900 & 0.710 & 22 \\
\hline 35 & 111 & 38 & 50 & 130 & 10 & 6 & 0.468 & 0.831 & 0.935 & 0.744 & 12 \\
\hline 36 & 111 & 38 & 40 & 130 & 10 & 6 & 0.504 & 0.746 & 0.958 & 0.736 & 15 \\
\hline 37 & 113 & 41 & 34 & 140 & 9 & 5 & 0.789 & 0.607 & 0.335 & 0.577 & 45 \\
\hline 38 & 109 & 41 & 46 & 140 & 11 & 7 & 0.407 & 0.865 & 0.975 & 0.749 & 10 \\
\hline 39 & 109 & 41 & 54 & 120 & 9 & 5 & 0.355 & 0.790 & 0.910 & 0.685 & 33 \\
\hline 40 & 113 & 41 & 54 & 120 & 11 & 5 & 0.479 & 1.000 & 0.982 & 0.820 & 3 \\
\hline 41 & 109 & 41 & 54 & 120 & 11 & 7 & 0.356 & 0.946 & 0.934 & 0.745 & 11 \\
\hline 42 & 109 & 35 & 46 & 120 & 11 & 7 & 0.452 & 0.814 & 0.950 & 0.738 & 34 \\
\hline 43 & 111 & 38 & 59 & 130 & 10 & 6 & 0.393 & 0.673 & 0.892 & 0.653 & 37 \\
\hline 44 & 113 & 41 & 46 & 120 & 9 & 5 & 0.580 & 0.642 & 0.961 & 0.728 & 18 \\
\hline 45 & 113 & 35 & 46 & 120 & 11 & 5 & 0.872 & 0.632 & 0.949 & 0.818 & 4 \\
\hline 46 & 106 & 38 & 50 & 130 & 10 & 6 & 0.333 & 0.367 & 0.821 & 0.507 & 51 \\
\hline 47 & 111 & 38 & 50 & 130 & 10 & 8 & 0.508 & 0.589 & 0.904 & 0.667 & 34 \\
\hline 48 & 113 & 35 & 46 & 140 & 9 & 5 & 1.000 & 0.630 & 0.845 & 0.825 & 2 \\
\hline 49 & 113 & 35 & 54 & 140 & 9 & 7 & 0.999 & 0.626 & 0.890 & 0.838 & 1 \\
\hline 50 & 111 & 38 & 50 & 130 & 10 & 6 & 0.617 & 0.622 & 0.946 & 0.728 & 17 \\
\hline 51 & 109 & 41 & 46 & 120 & 11 & 5 & 0.462 & 0.720 & 0.545 & 0.576 & 46 \\
\hline 52 & 111 & 38 & 50 & 106 & 10 & 6 & 0.571 & 0.667 & 0.618 & 0.619 & 42 \\
\hline
\end{tabular}


The grey relation coefficient and grade (GRG) for each run was calculated and ranked from 1 to 52 (Table 5). The GRG with highest rank determine the optimum combination of input factors; experiment number 49 had the highest grade. GRG of 0.838 was obtained in $\mathrm{A}_{4} \mathrm{~B}_{2} \mathrm{C}_{4} \mathrm{D}_{4} \mathrm{E}_{2} \mathrm{~F}_{4}$ run (Table 5).

Basically, larger the GRG, better the MRR, SR and WWR (Raghuraman et al., 2013). Experiment 49 had optimum settings of machining parameter i.e. $\mathrm{A}_{4} \mathrm{~B}_{2} \mathrm{C}_{4} \mathrm{D}_{4} \mathrm{E}_{2} \mathrm{~F}_{4}$ at which $\mathrm{MRR}$ was $36.130 \mathrm{~mm}^{2} / \mathrm{min}$, SR was $2.842 \mu \mathrm{m}$ and WWR was 0.01832 among 52 experiments. The roughness curve for optimum combination of input factors i.e. $\mathrm{A}_{4} \mathrm{~B}_{2} \mathrm{C}_{4} \mathrm{D}_{4} \mathrm{E}_{2} \mathrm{~F}_{4}$ is shown in Fig. 5.

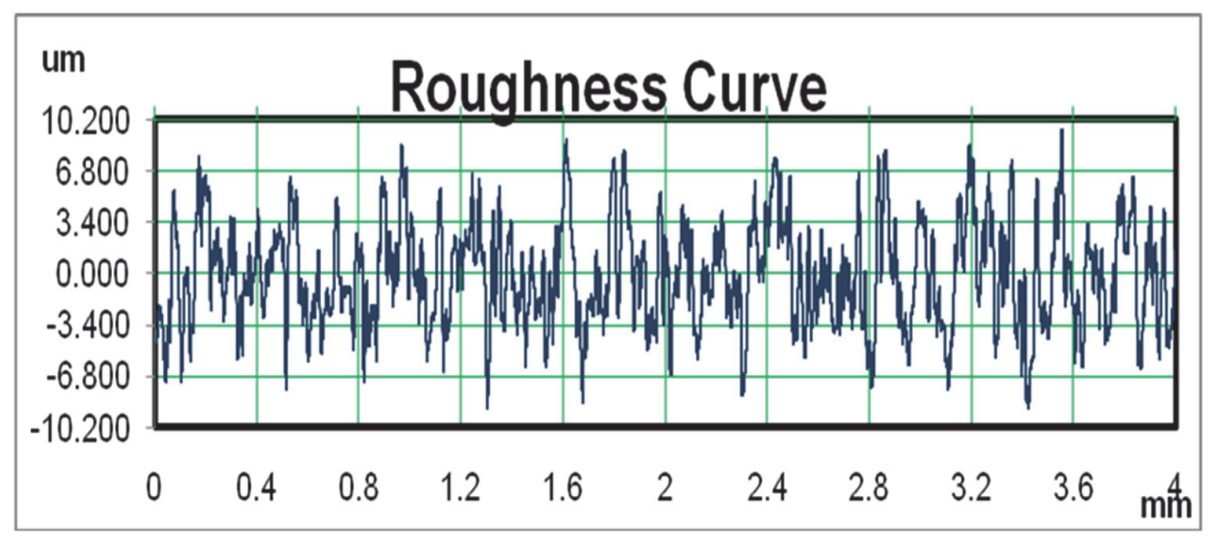

Fig. 5. Roughness curve for optimum setting of control factors $\left(\mathrm{A}_{4} \mathrm{~B}_{2} \mathrm{C}_{4} \mathrm{D}_{4} \mathrm{E}_{2} \mathrm{~F}_{4}\right)$

\subsection{Grey Predicted theory}

Since the design used for experimentation is orthogonal, it is possible to separate out the effect of each machining parameter on the grey relational grade at different levels (Guo et al., 2016). For this, the average of the GRG for each input factor is calculated at five different levels from Table 5. The mean of the grey relational grade for each level of the machining parameters is summarized and shown in Table 6 . The larger the grey relational grade, the better is the multiple performance characteristics (Raghuraman et al., 2013). The optimal combination of the machining parameter levels was determined as $\mathrm{A}_{4} \mathrm{~B}_{1} \mathrm{C}_{1} \mathrm{D}_{5} \mathrm{E}_{4} \mathrm{~F}_{2}$ from Table 6 . The comparative importance among each machining parameters was calculated by finding the difference between maximum and minimum value of GRG of corresponding input factors at each level. It was found that $\mathrm{T}_{\text {on }}$ is the most significant factor followed by WF, $\mathrm{T}_{\text {off, }}$ IP, $\mathrm{SV}$, and WT (Table 6). $\mathrm{T}_{\text {on }}$ was found to be the most significant input parameter for MRR, SR and WWR in other reports (Goswami and Kumar, 2014; Kumar et al., 2011; Meena and Azad, 2012).

Table 6

Response data for Grey Relational Grade

\begin{tabular}{ccccccccc}
\hline & & \multicolumn{9}{c}{ Grey Relational Grade } & & & \\
\hline Symbol & Process Parameter & Level-1 & Level-2 & Level-3 & Level-4 & Level-5 & Max-min & Rank \\
\hline A & Ton & 0.507 & 0.670 & 0.675 & $\mathbf{0 . 7 1 9}^{*}$ & 0.699 & 0.213 & 1 \\
B & Toff & $\mathbf{0 . 7 6 5}^{*}$ & 0.715 & 0.663 & 0.675 & 0.662 & 0.102 & 3 \\
C & SV & $\mathbf{0 . 7 3 6}^{*}$ & 0.693 & 0.665 & 0.697 & 0.653 & 0.083 & 5 \\
D & IP & 0.619 & 0.685 & 0.668 & 0.705 & $\mathbf{0 . 7 2 0}^{*}$ & 0.101 & 4 \\
E & WT & 0.702 & 0.677 & 0.664 & $\mathbf{0 . 7 1 3}^{*}$ & 0.704 & 0.010 & 6 \\
F & WF & 0.516 & $\mathbf{0 . 6 9 8}^{*}$ & 0.676 & 0.692 & 0.667 & 0.182 & 2 \\
\hline
\end{tabular}

\subsection{Confirmation Tests}

The concluding step of the machining of Inconel 825 was to predict and verify improvement in MRR, SR and WWR with respect to the selected input parameters. For this, the confirmation test is performed and the results obtained were compared with the outcomes of RSM and the results predicted by grey theory. Table 7 shows the comparative results of experiment No. 49; grey theory optimal design 
$\mathrm{A}_{4} \mathrm{~B}_{1} \mathrm{C}_{1} \mathrm{D}_{5} \mathrm{E}_{4} \mathrm{~F}_{2}$ process parameters and actual experimental results obtained at grey theory predicted optimal parameters setting in WEDM of Inconel 825 alloy workpiece material.

Table 7

Performance results using the initial orthogonal array and optimal grey predicted process parameter

\begin{tabular}{|c|c|c|c|c|}
\hline \multicolumn{5}{|c|}{ Optimal Process Parameters } \\
\hline Response & Orthogonal Array & Grey Theory Prediction & Experimental & $\%$ error \\
\hline Parameters & $\mathrm{A}_{4} \mathrm{~B}_{2} \mathrm{C}_{4} \mathrm{D}_{4} \mathrm{E}_{2} \mathrm{~F}_{4}$ & $\mathrm{~A}_{4} \mathrm{~B}_{1} \mathrm{C}_{1} \mathrm{D}_{5} \mathrm{E}_{4} \mathrm{~F}_{2}$ & $\mathrm{~A}_{4} \mathrm{~B}_{1} \mathrm{C}_{1} \mathrm{D}_{5} \mathrm{E}_{4} \mathrm{~F}_{2}$ & \\
\hline MRR & 36.13 & 40.220 & 41.828 & 3.84 \\
\hline SR & 2.842 & 2.547 & 2.445 & 4.01 \\
\hline WWR & 0.01832 & -0.0438 & 0.01758 & 3.49 \\
\hline
\end{tabular}

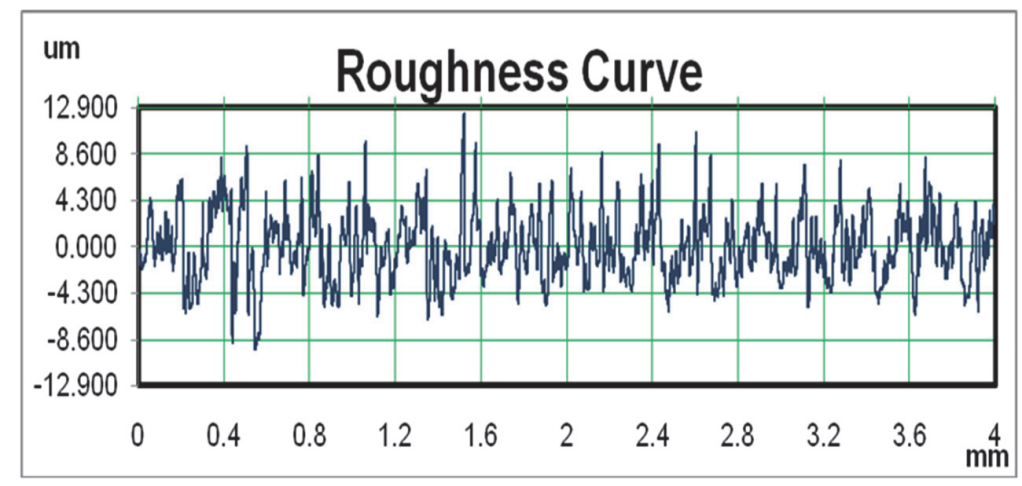

Fig. 6. Roughness curve for confirmation experiment $\left(\mathrm{A}_{4} \mathrm{~B}_{1} \mathrm{C}_{1} \mathrm{D}_{5} \mathrm{E}_{4} \mathrm{~F}_{2}\right)$

According to results obtained, MRR increased from $36.130 \mathrm{~mm}^{2} / \mathrm{min}$ to $41.828 \mathrm{~mm}^{2} / \mathrm{min}$, SR decreased from $2.842 \mu \mathrm{m}$ to $2.445 \mu \mathrm{m}$ and WWR slightly decreased from 0.01832 to 0.01758 (Table 7 ). The subsequent improvement in MRR is $13.62 \%$ whereas SR and WWR is reduced by $13.97 \%$ and $4.03 \%$ respectively. In the only study reported so far, MRR was improved by $7.22 \%$ and surface roughness is reduced by $16.66 \%$ (Goswami et al., 2014). WWR was not studied by anyone as evidenced from the literature review. Fig. 6 shows the roughness curve for confirmation experiment i.e. $\mathrm{A}_{4} \mathrm{~B}_{1} \mathrm{C}_{1} \mathrm{D}_{5} \mathrm{E}_{4} \mathrm{~F}_{2}$.

As the predicted results are found to be in good compliance with the experimental results and the error is less than $\pm 5 \%$, therefore, the developed model is successfully validated.

\subsection{Microstructure analysis of machined surface of specimens $A_{4} B_{2} C_{4} D_{4} E_{2} F_{4}$ and $A_{4} B_{1} C_{1} D_{5} E_{4} F_{2}$}

SEM was performed to analyze the surface topography of machined surface. The surface irregularities includes micro-cracks, pockmarks, craters, and spherical nodules, debris and melted material deposits, heat affected zone, and recast layer. During the machining process, rapid heating and cooling of the work surface produces thermal and tensile stress on work material surface which causes crack formation (Daneshmand et al., 2013).

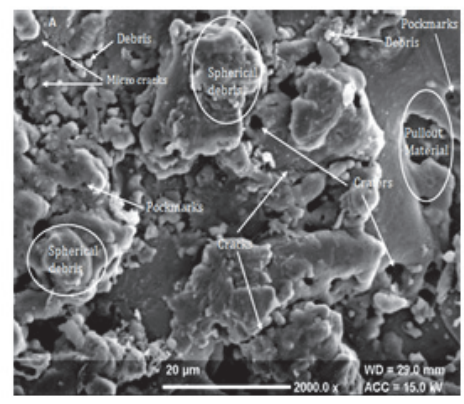

A

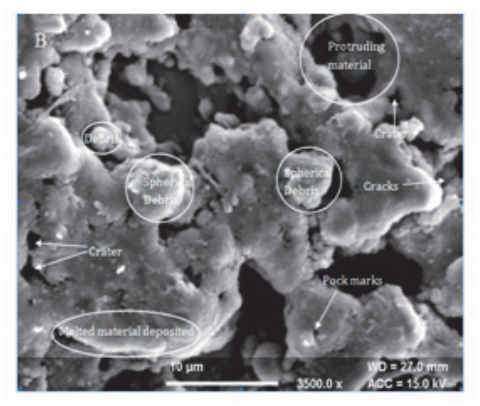

B

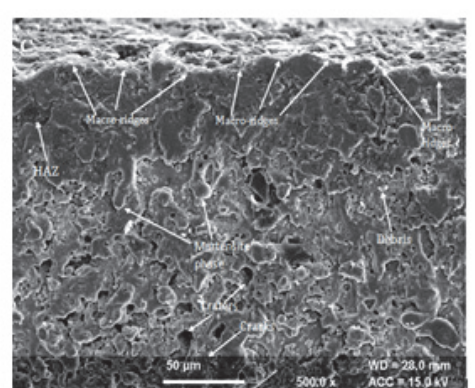

C

Fig. 7. SEM Micrograph of $\mathrm{A}_{4} \mathrm{~B}_{2} \mathrm{C}_{4} \mathrm{D}_{4} \mathrm{E}_{2} \mathrm{~F}_{4}$ WEDM-cut surface of Inconel 825 at different cross section 
Due to tensile stress present in sample, not all of the melted material was swept away from the work material surface by the dielectric fluid but some of the material remains on the work surface during solidification. At that time stress present in material exceeded the material's ultimate tensile strength resulted in crater formation (Daneshmand et al., 2013). From the SEM micrograph, it was observed that craters, pockmarks, pull out materials and cracks were less in the combination $\mathrm{A}_{4} \mathrm{~B}_{2} \mathrm{C}_{4} \mathrm{D}_{4} \mathrm{E}_{2} \mathrm{~F}_{4}$ Fig. 7 (A-B) as compared to the combination $\mathrm{A}_{4} \mathrm{~B}_{1} \mathrm{C}_{1} \mathrm{D}_{5} \mathrm{E}_{4} \mathrm{~F}_{2}$ Fig. 8 (a-b).

This can be due to reason that the high value of peak current and low value of pulse-off time resulted in increased rate of discharge energy in the spark gap which causes more evaporation of work material resulting in large number of craters and cracks in the combination $\mathrm{A}_{4} \mathrm{~B}_{1} \mathrm{C}_{1} \mathrm{D}_{5} \mathrm{E}_{4} \mathrm{~F}_{2}$ Fig. 8 (A-B). Surface irregularities of the machined surface were also characterized by the presence of two zones i.e. heat affected zone (HAZ) and recast layer (RL). By the application of gap voltage the work material surface reached the melting temperature and re-solidified on the work surface and recast layer formed due to the deposition of the effected material in the form of macro ridges and pull-out material (Çaydas and Ay, 2016; Gostimirovic et al., 2012).

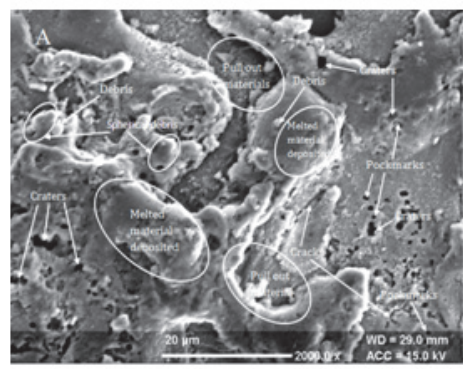

A

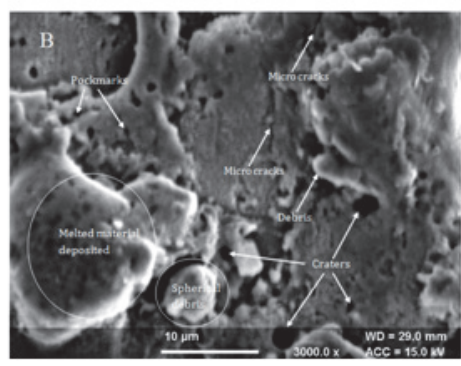

B

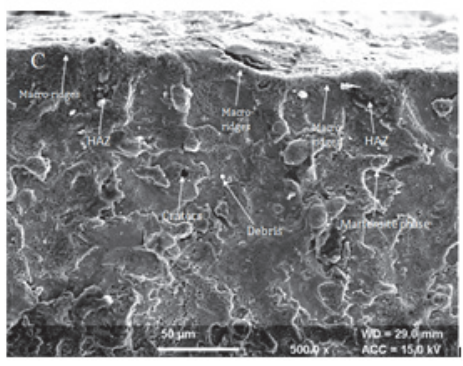

C

Fig. 8. SEM Micrograph of $A_{4} B_{1} C_{1} D_{5} E_{4} F_{2}$ WEDM-cut surface of Inconel 825 at different cross section

Below the recast layer, there is heat-affected zone which is formed due to less temperature of the work surface below the recast layer (Çaydas and Ay, 2016). A visible martensite structure was also observed from SEM micrograph (Fig. 7C and Fig. 8C). Minor hillocks, valleys and macro-ridges were observed less in numbers at optimum combination of process parameters $\mathrm{A}_{4} \mathrm{~B}_{1} \mathrm{C}_{1} \mathrm{D}_{5} \mathrm{E}_{4} \mathrm{~F}_{2}$ (Fig. 8C) as compared to the combination $\mathrm{A}_{4} \mathrm{~B}_{2} \mathrm{C}_{4} \mathrm{D}_{4} \mathrm{E}_{2} \mathrm{~F}_{4}$ (Fig. 7C). Because at low value of pulse off time and gap voltage more melted material ejected by the dielectric pressure in spark gap area, therefore, less number of macro-ridges and minor hillocks were observed from SEM micrograph (Fig. 8C).

\section{Conclusions}

In the present study, the effects of WEDM characteristics on MRR, SR and WWR in machining of Inconel 825 superalloy were studied.

1. From the grey relation theory, it was found that, optimal set of process parameter had the most significant effect on MRR, SR and WWR.

2. $\mathrm{T}_{\mathrm{on}}, \mathrm{WF}, \mathrm{T}_{\mathrm{off}}$, IP was the most contributing factor for MRR, SR, and WWR followed by SV and WT.

3. The multi-response optimization resulted in $13.62 \%$ improvement in MRR.

4. SR and WWR were reduced by $13.97 \%$ and $4.03 \%$ respectively.

5. Thus, the established mathematical model can be used in industry for the machining of Inconel 825 using WEDM.

The developed method will result in improve productivity and reduced roughness of Inconel 825 in aero space industry. The optimum parametric combination obtained from the present study will be advantageous for working on high strength, high thermal conductivity and low melting point materials like nickel alloys even at higher temperatures. 


\section{References}

Aggarwal, V., Khangura, S.S. \& Garg, R.K. (2015). Parametric modeling and optimization for wire electrical discharge machining of Inconel 718 using response surface methodology. International Journal of Advanced Manufacturing Technology, 79, 31-47.

AKCA, E. \& Gursel A. (2013). A review on Superalloys and IN718 Nickel-Based INCONEL Superalloy. Periodicals of Engineering and Natural Sciences, 3(1), 15-27.

Çaydas, U. \& Ay, M. (2016). WEDM cutting of Inconel 718 nickel-based superalloy: effects of cutting parameters on the cutting quality. Materials and Technology, 1, 117-125.

Chhabra, S., Gupta, D. \& Yadav, P. (2014). Optimizing the Process Parameters of WEDM using Taguchi Technique on P21 die steel. International Journal of Innovative Research in Science, Engineering and Technology, 3(7), 14815-14821.

Choi, K.K., Nam, W.J. \& Lee, Y.S. (2008). Effects of heat treatment on the surface of a die steel STD 11 machined by WEDM. Journal of Material Processing Technology, 201(1-3), 580-584.

Dabade, U.A. \& Karidkar, S.S. (2016). Analysis of response variables in WEDM of Inconel 718 using Taguchi technique. Procedia CIRP, 41, 886 - 891.

Daneshmand, S., Kahrizi, E.F., Abedi, E. \& Abdolhosseini, M.M. (2013). Influence of machining parameters on electro discharge machining of NiTi shape memory alloys. International Journal of Electrochemical Science, 8, 3095 - 3104.

Gostimirovic, M., Kovac, P., Sekulic, M. \& Skoric, B. (2012). Influence of discharge energy on machining characteristics in EDM. Journal of Mechanical Science and Technology, 26(1), 173-179.

Goswami, A. \& Kumar, J. (2014). Investigation of surface integrity, material removal rate and wire wear ratio for WEDM of Nimonic 80A alloy using GRA and Taguchi method. Engineering Science and Technology, an International Journal, $17(4), 173-184$.

Guo, Y., Wang, L., Zhang, G., \& Hou, P. (2017). Multi-response optimization of the electrical discharge machining of insulating zirconia. Materials and Manufacturing Processes, 32(3), 294-301.

Kumar, A., Maheshwari, S., Sharma, C. \& Beri, N. (2011). Analysis of machining characteristics in additive mixed electric discharge machining of nickel-based superalloy Inconel 718. Materials and Manufacturing Processes, 26(8), 10111018.

Mahapatra, S. S., \& Patnaik, A. (2007). Optimization of wire electrical discharge machining (WEDM) process parameters using Taguchi method. The International Journal of Advanced Manufacturing Technology, 34(9), 911-925.

Meena, V.K. \& Azad, M.S. (2012). Grey relational analysis of micro-EDM machining of Ti-6Al-4V alloy. Materials and Manufacturing Processes, 27(9), 973-977

Patra, D.R., Rout, I.S. \& Sahoo, M. (2015). Optimization of WEDM parameters using Taguchi method for higher material removal rate on EN31 steel. International Journal of Engineering Research and Applications, 5(6), 57-62.

Raghuraman, S., Thiruppathi, K., Panneerselvam, T. \& Santosh, S. (2013). Optimization of EDM parameters using Taguchi method and grey relational analysis for mild steel IS 2026. International Journal of Innovative research in Science, Engineering and Technology, 2(7), 3095-3104.

Rajyalakshmi, G. \& Venkata Ramaiah, P. (2013a). Multiple process parameter optimization of wire electrical discharge machining on Inconel 825 using Taguchi grey relational analysis. International Journal of Advanced Manufacturing Technology, 69(5-8): 1249-1262.

Rajyalakshmi, G. \& Venkata Ramaiah, P. (2012). A parametric optimization using Taguchi method: effect of WEDM parameters on surface roughness machining on Inconel 825. Elixir Mechanical Engineering, 43, 6669-6674.

Rajyalakshmi, G. \& Venkata, R.P. (2013b). Optimization of process parameters of wire electrical discharge machining using fuzzy logic integrated with Taguchi method. International Journal of Scientific Engineering and Technology, 2(6), 600-606.

Raykundaliya, D.P. \& Shanubhogue, A. (2015). Comparison Study: Taguchi Methodology vis.-a-vis. Response Surface Methodology through a case study of accelerated failure in Spin-on-Filter. International Advanced Research Journal in Science, Engineering and Technology, 2(3), 1-5.

Singh, V.K. \& Singh, S. (2015). Multi-objective optimization using Taguchi Based Grey Relational Analysis for Wire EDM of Inconel 625. Journal of Material Science and Mechanical Engineering, 2(11), 38-42.

Singha, A., Anandita, S. \& Gangopadhyay, S. (2015). Microstructural analysis and multiresponse optimization during ECM of Inconel 825 using hybrid approach. Material and Manufacturing Processes, 30(7), 842-851.

Somashekhar, K.P., Ramachandran, N. \& Mathew, J. (2010). Optimization of material removal rate in micro-edm using artificial neural network and genetic algorithms. Material and Manufacturing Processes, 25(6), 467-475.

Thakur, A., Mohanty, A., Gangopadhyay, S. \& Maity, K.P. (2014). Tool wear and chip characteristics during dry turning of Inconel 825. Procedia Materials Science, 5, 2169-2177.

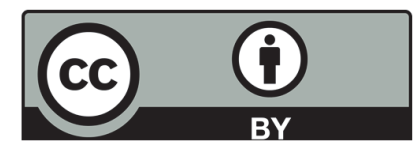

(C) 2018 by the authors; licensee Growing Science, Canada. This is an open access article distributed under the terms and conditions of the Creative Commons Attribution (CC-BY) license (http://creativecommons.org/licenses/by/4.0/). 